\title{
GRANULAR ACUTE LYMPHOBLASTIC LEUKEMIA IN A PAEDIATRIC PATIENT- A RARE CASE REPORT
}

\author{
Priyanka Yadavㄹ, Rajendra Kumar Nigam², Varsha Rampuri3 , Abhinav Junwal', Nihan Khan ${ }^{5}$
}

1MD Candidate, Department of Pathology, Gandhi Medical College, Bhopal, Madhya Pradesh, India.

2Professor, Department of Pathology, Gandhi Medical College, Bhopal, Madhya Pradesh, India.

${ }_{3}^{3}$ Assistant Professor, Department of Pathology, Gandhi Medical College, Bhopal, Madhya Pradesh, India.

${ }_{4}^{4}$ MD Candidate, Department of Pathology, Gandhi Medical College, Bhopal, Madhya Pradesh, India.

${ }_{5}^{5}$ D Candidate, Department of Pathology, Gandhi Medical College, Bhopal, Madhya Pradesh, India.

HOW TO CITE THIS ARTICLE: Yadav P, Nigam RK, Rampuri V, et al. Granular acute lymphoblastic leukemia in a paediatric patienta rare case report. J. Evolution Med. Dent. Sci. 2019;8(07):469-471, DOI: 10.14260/jemds/2019/104

\section{PRESENTATION OF CASE}

A one-year male child presented with pyrexia, periorbital puffiness and excessive cry for 8 days. No history of melena or blood loss. The infant's birth history and medical history were unremarkable. His development was normal, and he had no unusual dietary intake.

Physical examination revealed a well-developed, irritable male infant. His temperature was $38.9^{\circ} \mathrm{C}$; pulse $186 / \mathrm{min}$; respirations $32 / \mathrm{min}$; oxygen saturation $95 \%$ on room air; and weight, $7.5 \mathrm{~kg}$ (25th percentile for his age). He had pallor, distended abdomen and hepatosplenomegaly, with a liver edge palpable $5 \mathrm{~cm}$ below the right costal margin and a spleen tip palpable $4 \mathrm{cms}$ below the left costal margin. Abdominal ultrasound revealed liver of $12 \mathrm{~cm}$ and spleen of $15 \mathrm{~cm}$ size.

\section{CLINICAL DIAGNOSIS}

Leukemia

\section{DIFFERENTIAL DIAGNOSIS}

- $\quad$ Acute Lymphoid Leukemia (ALL)

- $\quad$ Acute Myeloid Leukemia (AML)

- Leukemoid Reaction due to some infection or severe nutritional anaemia.

\section{PATHOLOGICAL DISCUSSION}

Haemogram revealed bi-cytopenia with $\mathrm{Hb}-7.0 \mathrm{gm} / \mathrm{dl}$ and platelets $56 \times 10^{3} / \mu$ l. However, there was leukocytosis with total leucocyte count of $280 \times 10^{3} / \mu \mathrm{l}$. Differential revealed $85 \%$ blasts, $08 \%$ lymphocytes and $07 \%$ neutrophils.

Peripheral smear stained with Leishman stain revealed $85 \%$ blasts, morphologically lymphoblasts -little variation in size of blast population, round to oval nuclei, finely granular chromatin with dispersed foci of condensation, scanty to moderate amount of basophilic cytoplasm and inconspicuous nucleoli. $30 \%$ of blasts showed coarse intracytoplasmic granules [Figure 1]. No Auer rods were found.

Bone marrow aspirate revealed hypercellular marrow with marked depletion of all three elements, i.e., erythroid,

'Financial or Other Competing Interest': None.

Submission 30-12-2018, Peer Review 31-01-2019,

Acceptance 07-02-2019, Published 18-02-2019.

Corresponding Author:

Dr. Rajendra Kumar Nigam,

Department of Pathology,

Gandhi Medical College,

Sultania Road, Near Hamidia Hospital,

Bhopal-462001, Madhya Pradesh, India.

E-mail: dr.rajendranigam@gmail.com

DOI: $10.14260 /$ jemds $/ 2019 / 104$ myeloid and megakaryocytic. $80 \%$ cells were blasts, morphologically similar to peripheral smear blasts with high nuclear to cytoplasmic ratio, scanty to moderate cytoplasm and inconspicuous nucleoli. Intracytoplasmic coarse granules were observed in $40 \%$ of blasts [Figure 2]. These granules were small to medium sized light pink to dark purple. Several granular blasts tended to form small clusters, a feature more commonly seen in ALL [Figure 2]. No Auer rods were identified.

Cytochemical analysis was in favor of ALL as blasts were PAS positive with fine and coarse granular positivity and completely negative for MPO [Figure 3]. On the basis of morphology and cytochemical studies, a definitive diagnosis of Granular ALL was made. The patient was advised immunophenotyping and cytogenetics for which he was referred to higher center; however, patient was lost to follow up.

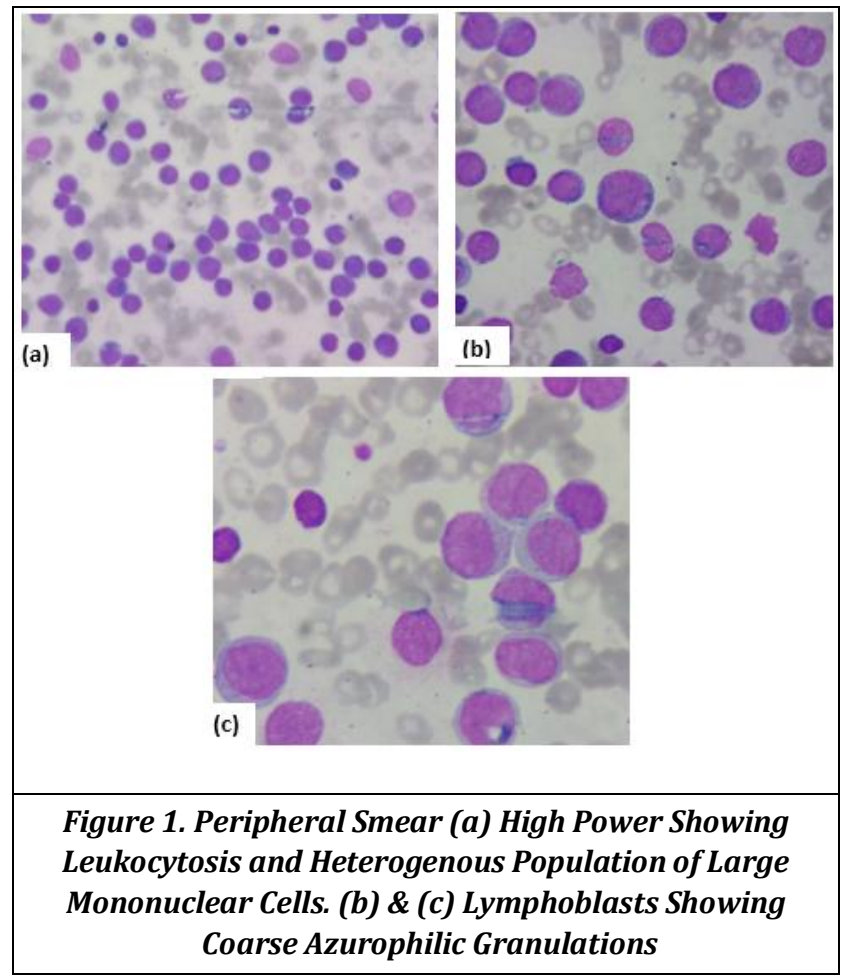



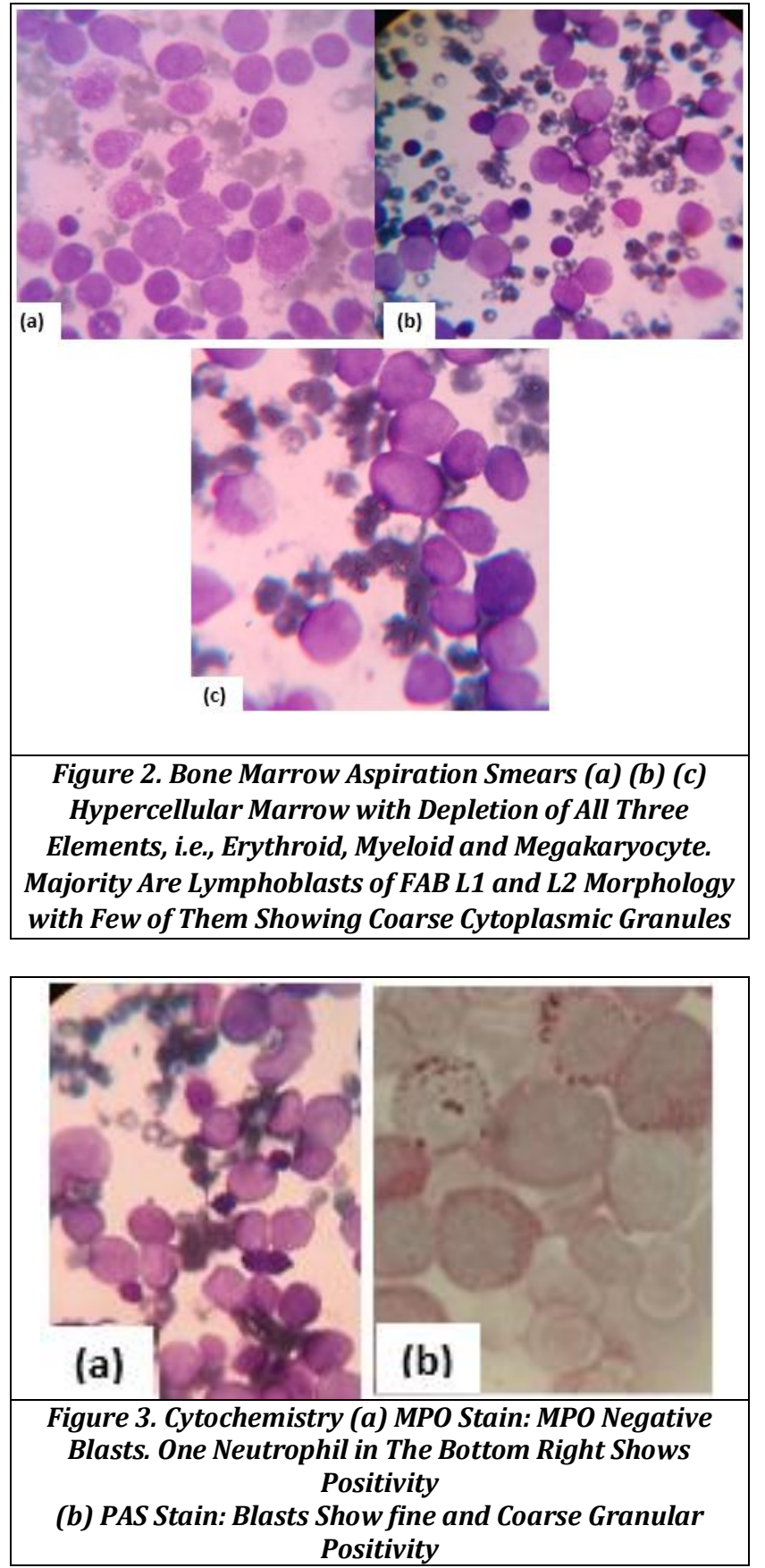

\section{DISCUSSION}

WHO Classification is now regarded as gold standard for leukemia diagnosis which combines morphology, cytochemistry, immunophenotyping, clinical presentation and genetic abnormalities. But in majority of centers in developing countries including our country, all these facilities are not available. In such cases, morphology and cytochemical evaluation of peripheral blood and/or bone marrow aspirate smears can give initial clue to diagnosis. Further, these patients can be referred early to the higher centers for immunophenotyping and cytogenetics after which specific therapy can be started at the earliest, as if not treated, such cases are rapidly fatal.

G-ALL may create diagnostic confusion with AML due to the presence of cytoplasmic granules found in the lymphoblasts.[1-5] This rare variant of ALL is commonly seen in children. In a large study by Paediatric Oncology Group (POG),[6] Granular ALL was identified in 56 out of the 1252 cases, more commonly in FAB L2 subtype of acute leukemia (4.5\%). Others have found similar occurrence in paediatric population ranging from $2-7 \%$ of childhood ALL cases. $[7],[1],[3],[4]$ Rare occurrences have been reported in adults. [3],[2],[8],[4],[9]

Granular ALL has been defined largely as having more than $1 \%$ of lymphoblasts having at least three or more clearly defined azurophilic granules.[1] However, most of studies have reported cases with more than $5 \%$ of lymphoblasts with small numbers of distinctive azurophilic granules. The pathogenesis of granules of granular ALL has been hypothesized as being the result of dysplastic organella formation, fusion, or degeneration.[7],[2] These granular lymphoblasts are positive for PAS, may occasionally also be positive for Sudan Black B, causing further confusion with myeloid blasts, $[7],[2]$ however they are completely negative for myeloperoxidase which is a more specific marker for myeloid differentiation. However in few cases, Immuno-phenotyping by flow cytometry and/or immunohistochemistry would be crucial for lineage determination if morphologic and cytochemical features are equivocal.[7],[2],[3],[10],[11],[12]

\section{FINAL DIAGNOSIS}

Granular ALL

With high degree of clinical suspicion, especially in childhood population, even the presence of granules in lymphoblast like cells with absence of Auer rods should prompt evaluation by cytochemistry. Negativity for MPO and positivity for PAS will clinch the diagnosis of Granular ALL which can further be confirmed by Immunophenotyping. Diagnosing this rare variant-Granular ALL is important as it has worse prognosis than other forms of ALL and requires early intensive intervention.

\section{ACKNOWLEDGEMENTS}

We are thankful to Dr. Reeni Malik, Prof. and Head Dept. of Pathology GMC, Bhopal for providing general support for our study. Thanks to all the faculty and technical staff of Dept. of Pathology, GMC, Bhopal who provided both technical as well as general support.

\section{REFERENCES}

[1] Foucar K. Bone Marrow Pathology. 2nd edn. Chicago: ASCP Press 2001: p. 484-514.

[2] Invernizzi R, Rosanda C, Basso G, et al. Granular acute lymphoblastic leukemia in children. "Aieop Cooperative Group for Cytology of Acute Leukemias". Haematologica 1992;77(1):30-4.

[3] Stein P, Peiper S, Butler D, et al. Granular acute lymphoblastic leukemia. Am J Clin Pathol 1983;79(4):426-30.

[4] Cantù-Rajnoldi A, Invernizzi R, Biondi A, et al. Biological and clinical features of acute lymphoblastic leukaemia with cytoplasmic granules or inclusions: description of eight cases. $\mathrm{Br} \mathrm{J}$ Haematol 1989;73(3):309-14.

[5] Anand H, Tyagi S. Granular acute lymphoblastic leukemia in an adult patient. Indian J Pathol Microbiol 2008;51(1):116-7.

[6] Tsoi WC, Lai HD, Feng CS. T-acute lymphoblastic leukemia with cytoplasmic granules. Am J Hematol 1997;56(3):193-4. 
[7] Takemori N, Saito N, Morioka M, et al. Peculiar cytoplasmic inclusions in acute lymphoblastic leukemia: cytochemical and electron microscopic observations. Am J Clin Pathol 1985;83(4):527-34.

[8] Darbyshire PJ, Lilleyman JS. Granular acute lymphoblastic leukaemia of childhood: a morphological phenomenon. J Clin Pathol 1987;40(3):251-3.

[9] Mohamed SF, Soliman DS, Helmy FI, et al. Granular lymphoblast in a case of acute lymphoblastic leukemia: a rare morphology. Int J Case Rep Images 2016;7(11):770-2.
[10] Pitman SD, Huang Q. Granular acute lymphoblastic leukemia: a case report and literature review. Am J Hematol 2007;82(9):834-7.

[11] Fradera J, Vélez-García E, White JG. Acute lymphoblastic leukemia with unusual cytoplasmic granulation: a morphologic, cytochemical and ultrastructural study. Blood 1986;68(2):406-11.

[12] Morita S, Saigo K, Kosaka Y, et al. Two cases of acute lymphoblastic leukemia with cytoplasmic granules. Rinsho Byori 2002;50(6):625-9. 